\title{
15 years of Rev Rene - a tribute to the Brazilian Nursing!
}

Alacoque Lorenzini Erdmann ${ }^{1}$

Congratulations to Rev Rene, Northeastern Nursing Network Journal (in Portuguese), for its fifteen years of existence consecrating important contributions to the science and profession of nursing. Congratulations to the Postgraduate Program in Nursing, to the Nursing Department and to the institution Federal University of Ceará that hosts this important structure of scientific dissemination.

Its trajectory certainly marks the challenges of intellectual work needed to materialize publications that are the fruit of several people; authors and teams in multiple instances and under various conditions, from the moment of generation of ideas of knowledge to be produced to the construction of the project, its execution and finally, the scientific paper submitted for publication, reviewed and approved, formatted and published. People, material and financial resources, appropriate logistical and legal systems for submission, analysis and editing to reach the most pleasant moment, the moment of seeing the article published.

In the same manner, editors and support staff celebrate the moment when the issue of the journal is available to readers. How many were these moments during these 15 years of life? Who and how many were the chief and section editors, consultants, translators, reviewers, typists, secretaries, managers and collaborators of this magazine? Which were the outstanding achievements of this life trajectory? What has been learned and what has boosted the desire to continue investing in its periodicity, consistency, relevance and purpose?

The other moment, the moment of reading or consuming these articles. Which were the indexers conquered? Who and how many are our interlocutors, those disclosed and those that benefit from such knowledge, either by the reading or by the citations and even by incorporating new practices? Which of the two languages, Portuguese or English, are the most accessed? Which issue had the greatest impact? How many issues, today bimonthly published, have already been edited? And, what was advanced after becoming electronically available?

Surely it is no longer a utopia but a reality of 15 years of existence. The dream and ideals of professors and researchers of the Brazilian northeast region's universities culminate with the expansion of postgraduate programs in nursing and need for creation of doctorate programs in nursing in this region, being the first doctorate program the one created at the Federal University of Ceará in 1998.

In this sense, the existence of a journal follows the policy of increment of supporting bases of these programs with the possibility to receive and impart quality to scientific production from other regions of the country and abroad. The journals, thus, feeds the advancement of its own lines of research, but also allows for publishing part of its production. The performance profile of postgraduate programs stricto sensu tends to be similar to the qualification profile of bond journals.

The Rev Rene has already gained major indexations with impact index measurements or lists of databases, namely: Bibliographic Databases of the Foundation Index (CUIDEN), Cumulative Index to Nursing and Allied Health Literature (CINAHL), Virtual Health Library (BVS), Nursing Journals Portal (Rev@Enf), Latin American and Caribbean Health Sciences Literature (LILACS), Latin American Science Magazines Index (PERIÓDICA), Online Information Regional System for Latin America, Caribbean, Spain and Portugal Scientific Journals

${ }^{1}$ Universidade Federal de Santa Catarina, PQ 1A of the CNPq. Florianópolis, SC, Brazil. 
(LATINDEX), EBSCO Publishing, Latin America and the Caribbean, Spain and Portugal Scientific Journals (REDALYC) and CAPES Periodicals Portal.

These indexations put the journal under international visibility and access, enabling the participation of foreign researchers and consequently resulting in greater impact in the scientific community and exposure to criticism, thus contributing to its strengthening as journal and to the advancement of nursing science. As it is bilingual and indexed in CUIDEN and CINAHL, the journal is already conquering the world in the nursing field.

Our hope is that new indexations of international circulation come to be achieved, with the confidence that the journal is already meeting the criteria of indexing organs of high quality scientific journals.

Brazilian Nursing has gained much with these 15 years of the journal RENE, adding strongholds in the academic environment and improving the quality of professional practice, especially in vocational themes of this journal. The best quality in training new professionals in undergraduate and graduate programs is the result and reflects the quality of our scientific publications, either in scope or in depth and complexity.

Congratulations and many thanks to all who contribute to the advancement of science and the nursing profession. Congratulations and acknowledgements to the Northeastern Nursing Network Journal - a tribute to the Brazilian Nursing! We offer our honors for its 15 years. 